\title{
Laryngeal Paralysis Recovered Two Years after a Head Trauma by Growth Hormone Treatment and Neurorehabilitation
}

\author{
Joaquín Guerra ${ }^{1, *(\mathbb{C}, \text { Hortensia Lema }}{ }^{2}$, Carlos Agra $^{3}$, Pedro Martínez ${ }^{4}$ and Jesús Devesa ${ }^{5, *(1)}$ \\ 1 Otolaryngology, Medical Center Foltra, 15894 Teo, Spain \\ 2 Speech Therapy, Medical Center Foltra, 15894 Teo, Spain; hortelema@gmail.com \\ Neurostimulation, Medical Center Foltra, 15894 Teo, Spain; carlosagra80@gmail.com \\ 4 Neuroradiology, Clínica Gaias, 15702 Santiago de Compostela, Spain; pedromartinezcueto@gmail.com \\ 5 Scientific Direction, Medical Center Foltra, 15894 Teo, Spain \\ * Correspondence: joaquin.guerra.otorrino@gmail.com (J.G.); jesus.devesa@usc.es (J.D.)
}

check for updates

Citation: Guerra, J.; Lema, H.; Agra, C.; Martínez, P.; Devesa, J. Laryngeal Paralysis Recovered Two Years after a Head Trauma by Growth Hormone Treatment and Neurorehabilitation. Reports 2021, 4, 19. https:/ / doi.org/ $10.3390 /$ reports 4030019

Academic Editor: Barbara Jarząb

Received: 27 May 2021

Accepted: 24 June 2021

Published: 28 June 2021

Publisher's Note: MDPI stays neutral with regard to jurisdictional claims in published maps and institutional affiliations.

Copyright: (c) 2021 by the authors. Licensee MDPI, Basel, Switzerland. This article is an open access article distributed under the terms and conditions of the Creative Commons Attribution (CC BY) license (https:// creativecommons.org/licenses/by/ $4.0 /)$.

\begin{abstract}
The aim of this study was to describe the cognitive and speech results obtained after growth hormone $(\mathrm{GH})$ treatment and neurorehabilitation in a man who suffered a traumatic brain injury (TBI). Seventeen months after the accident, the patient was treated with growth hormone (GH), together with neurostimulation and speech therapy. At admission, the flexible laryngoscopy revealed that the left vocal cord was paralyzed, in the paramedian position, a situation compatible with a recurrent nerve injury. Clinical and rehabilitation assessments revealed a prompt improvement in speech and cognitive functions and, following completion of treatment, endoscopic examination showed recovery of vocal cord mobility. These results, together with previous results from our group, indicate that GH treatment is safe and effective for helping neurorehabilitation in chronic speech impairment due to central laryngeal paralysis, as well as impaired cognitive functions.
\end{abstract}

Keywords: growth hormone; recurrent nerve injury; speech therapy; neurostimulation; vocal cord paralysis

\section{Introduction}

Laryngeal paralysis appears as a consequence of an injury along its path of the nerve fibers that innervate this structure. It can affect any point of the central regulatory centers, the main nerve branches that emerge from them and the nerves that directly innervate the larynx $[1,2]$. That is why the symptoms that may occur will depend on whether the affectation occurs at the level of the central nervous system (CNS) or the peripheral nervous system (PNS). In any case, a person affected by laryngeal paralysis can present diverse and variable symptoms such as dysphonia, dyspnea, and dysphagia, with a risk of aspiration. These are not only due to impaired vocal cord motility and the initial phases of swallowing, but also to loss of laryngopharyngeal sensitivity [3,4].

Due to its anatomical characteristics, in lesions of the laryngeal nerve (superior and inferior), the left side is usually the most affected, with the inferior laryngeal nerve (usually known as recurrent laryngeal nerve (RLN) being the most frequently damaged. This usually occurs due to endotracheal intubation [5,6], during any surgery, penetrating or blunt trauma, or direct manipulation of the nerve during surgery in the area that can cause dissection, inflammation, and nerve damage from compression or neuropraxia [4].

The incidence of upper vagus nerve injuries is rare compared to inferior laryngeal nerve injuries [3]. Causes of upper vagal injuries can be the result of traumatic brain injury, stroke, tumors, cervical damage, or they can occur as a consequence of neurosurgical interventions [4,7]. They can affect the brainstem, skull base, and carotid bifurcation, all of which are also associated with vagal neuropathy [8]. In traumatic causes, a plausible explanation for lower cranial nerve deficits after jugular foramen fracture was that some cranial nerves were directly compressed by displaced bone fragments [9] or due to dense 
ossification [10]. Recurrent bilateral nerve palsy after head injury is a rare clinical possibility but can be life-threatening if not diagnosed correctly [11]. Vascular events involving, for example, the posteroinferior cerebellar artery leading to occlusion, may involve the nucleus ambiguus on the dorsolateral area of the bulb, leading to loss of motoneurons in this zone. Therefore, stroke in this area may be the cause of ipsilateral vocal cord paralysis [12].

Currently, it is already well known that the administration of neurotrophic factors, such as growth hormone $(\mathrm{GH})$ or insulin-like growth factor-I (IGF-I), exerts important neuroprotective and neuroregenerative effects, both centrally and peripherally. In fact, our group was the first to achieve regeneration of vocal cords mobility in two cases: In one the damage had been caused by head trauma, with bulbar involvement [13], while in the other [14] the cause had been the removal of a bulbar astrocytoma that occurred in 1991 and was treated in 2006. In both cases, the recovery, after treatment with GH and neurorehabilitation, was complete, recovering mobility of the vocal cords, swallowing, etc. Later, a meta-analysis carried out by another group [15] confirmed our therapeutic approach, and gene therapy has recently been proposed for the treatment of this pathology [16].

In this study, we will describe the positive evolution of a patient, treated with $\mathrm{GH}$ and neurorehabilitation, who presented neurolaryngological and cognitive sequelae after a head trauma (TBI).

\section{Case Report}

\subsection{Medical Background}

A 57-year-old male patient, a former smoker, with no relevant medical history, suffered a fall from a ceiling 3 meters above the ground. When emergency services arrived at the scene of the accident, they observed occipital trauma and a low level of consciousness. He was transferred to the Emergency Service of a Spanish Third Level University Hospital, already presenting a right otorrhagia. A computerized tomography of the brain (Figure 1) revealed the existence of a subarachnoid hemorrhage and multiple skull fractures, mainly affecting the right occipital bone and extending to the condyle and occipital clivus. The patient was admitted to the intensive care unit (ICU).

In the following days, the patient developed intracranial hypertension refractory to medical treatment, for which a craniotomy with a left frontal lobectomy was performed. Subsequently, hydrocephalus and intracranial hypertension appeared, for which a ventriculoperitoneal bypass valve was placed. The patient was transferred back to the ICU, with a nasogastric tube and percutaneous tracheostomy. Initial phoniatric examination in the ICU showed a hypophonic voice, with poorly intelligible speech and poor articulatory definition. When trying to swallow with water, a cough appeared on the first sip, without desaturation. Subsequently, the patient began swallowing rehabilitation, which allowed the gradual reintroduction of liquid and solid oral nutrition.

During his stay in the ICU, the patient developed meningitis due to a ventricular catheter infection, which resolved with intravenous administration of meropenem and linezolid. A new ventriculoperitoneal bypass valve had to be placed, which he has been using ever since, and a titanium mesh cranioplasty was performed.

After experiencing a good medical evolution, the patient was transferred from the ICU to the rehabilitation area of the hospital, receiving hospital discharge 4 months later. Due to the existence of cognitive sequelae (limitation of executive functions due to apathy, and problems with verbal fluency, working memory, processing speed, and anosognosia) and neurolaryngological sequelae (mild dysphagia and hypophonia due to cord dysfunction), the patient began to attend to a Rehabilitation Center. In the subsequent follow-up, carried out at 5 months and 1 year after hospital discharge, the left vocal cord showed paralysis, in the paramedian position, a situation compatible with a recurrent nerve injury. The patient underwent cervical CT scan, not included in the article because it was normal. 


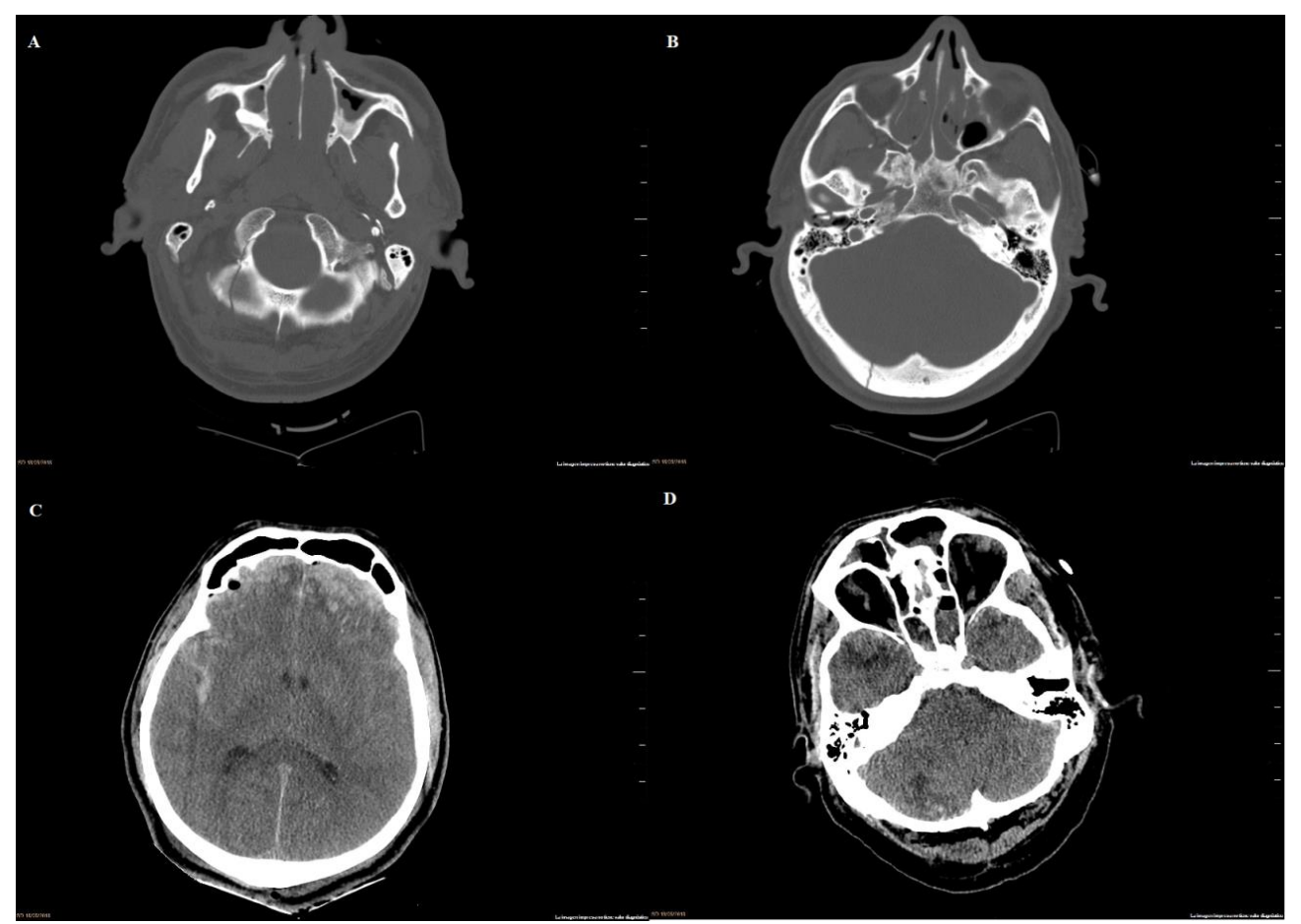

Figure 1. Computed tomography of the skull on admission to the emergency room: (A) linear fracture without displacement of the right occipital condyle and right part of the occipital bone scale; (B) fracture of the posterior wall of the right glenoid cavity with a fragment displaced toward the interior of the external ear canal. Cranial extension of the scale fracture is also observed. (C) Bilateral frontal cortical/subcortical contusions and subarachnoid hemorrhage. Brain edema. (D) Cortical contusions affecting the poles of the temporal lobes. Cortical contusion in the outer third of the right cerebellar hemisphere. Sinus liquid/gas levels compatible with hemorrhage.

Figure 2 shows the evolution of brain damage 1 year after the accident and before admission to the Medical Center Foltra.

\subsection{Medical Treatment}

After a blood test (hematometry, biochemistry, plasma levels of TSH and IGF-I, and tumoral markers CEA and PSA), a starting dose of GH of $1 \mathrm{mg} /$ day/5 days a week was prescribed for 1 month. Then, the dose was adjusted, according to the parameters of blood tests carried out after 1 month of treatment and every 3 months later, to $1 \mathrm{mg} / 3$ days a week for 3 months and finally at $0.8 \mathrm{mg} / 3$ days a week for 3 months. The treatment was approved by the Ethics Committee of the Foltra Medical Center and was carried out with the signed inform consent of the patient's legal representative and in accordance with national legislation and the Code of Ethical Principles for Medical Research on Human Beings of the World Medical Association (Declaration of Helsinki). No side effects attributable to the treatment carried out were observed, either during the treatment carried out or at discharge or after it. Only a slight increase in plasma IGF-I levels was observed, but within normal levels.

\subsection{Neurorehabilitation}

Rehabilitation included speech therapy and neurostimulation sessions 3 days a week, 45 min each, for 7 months. 


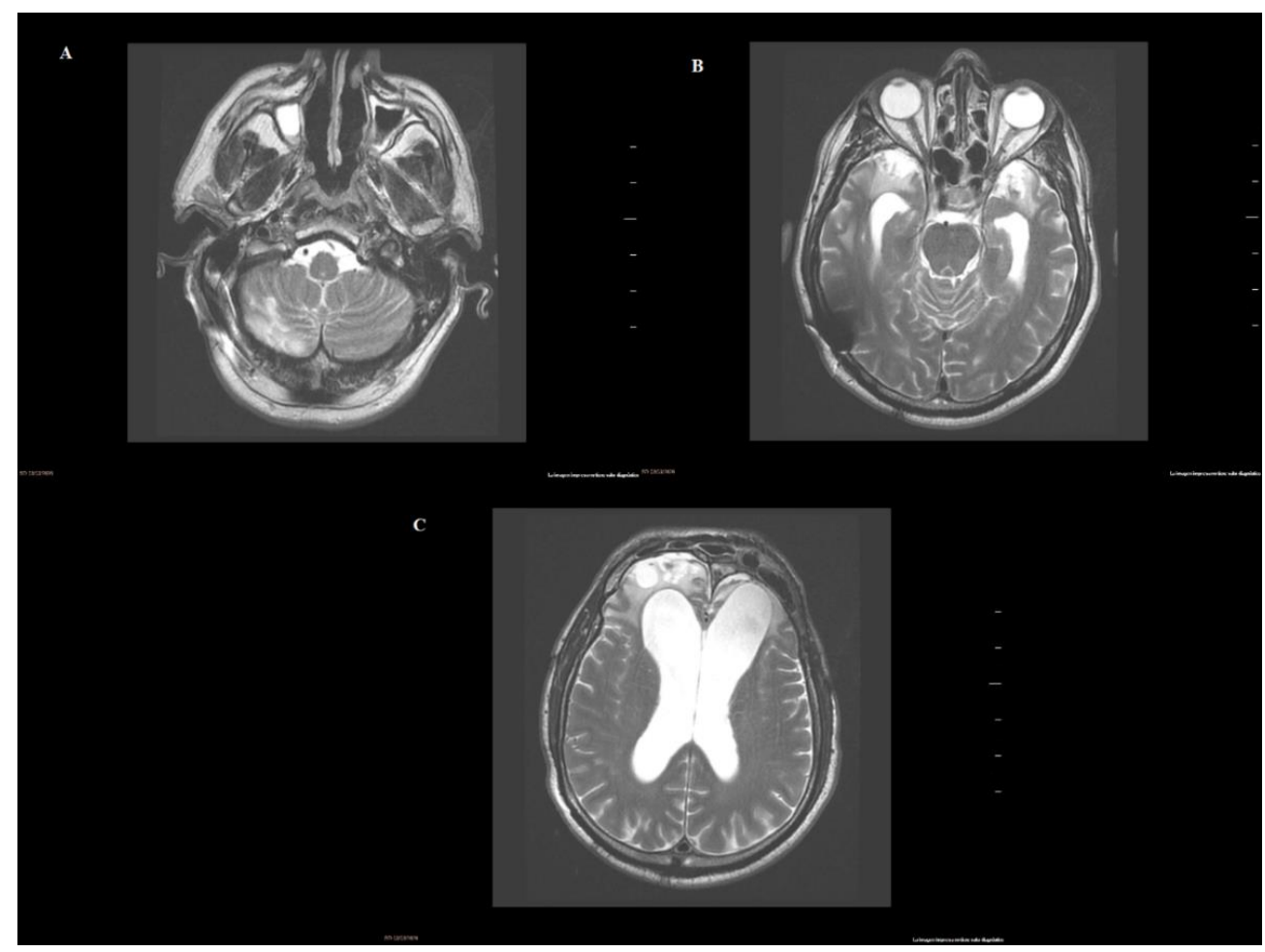

Figure 2. Evolutionary MRI: (A) Encephalomalacia of the external third of the right cerebellar hemisphere. (B) Bilateral temporal encephalomalacia. Ex vacuo dilatation of the ventricles. Bypass valve artifact at the right temporal cortex. (C) Bilateral frontal encephalomalacia with ex vacuo dilatation of the frontal horn.

\subsubsection{Speech Therapy}

The initial evaluation showed a marked tension in the masseter, cervical, and shoulder girdle muscles, with good execution of motor speech and mobility of the right tongue and palate. Before starting treatment, the GRABS perceptual evaluation of voice was 2-3-3-3-2 (values: $0=$ absence; $1=$ mild grade; $2=$ moderate grade; $3=$ severe grade). Therefore, exercises aimed at reducing muscle tension, vocal impedance activities, exercises to increase glottic coaptation without constriction, and vocal exercises with anatomical compensation of the affected side were carried out. Seven months later, the GRABS went to 1-2-2-2-1 (Figure 3). Speech modulation improved significantly. Although the patient was under the care of a single therapist, the speech therapy evaluation was performed by three different therapists, as we always do in these cases.

The re-evaluation showed recovery of the mobility of the left vocal cord, with complete opening, that is a normal cordal function, although slightly asymmetric and with some compensatory tension of the right laryngeal musculature (Figure 4). When performing forced inspiration and coughing, mobility is total and symmetrical (see supplementary video). 


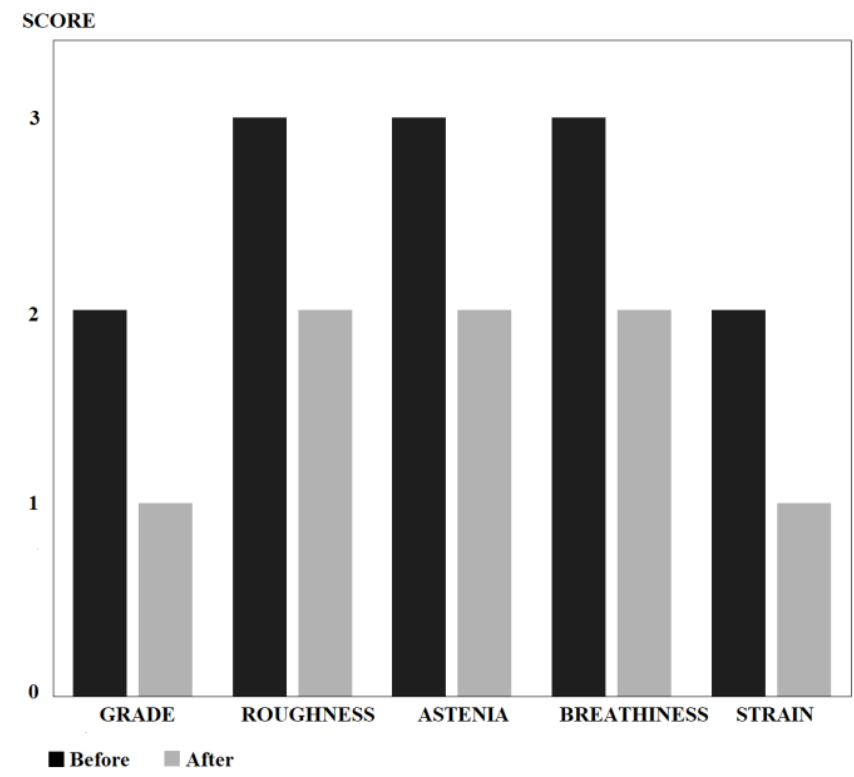

Figure 3. Results of the GRABS scale before and after treatment. Note how the initial predominantly hoarse and airy voice was reduced to mild/moderate levels.
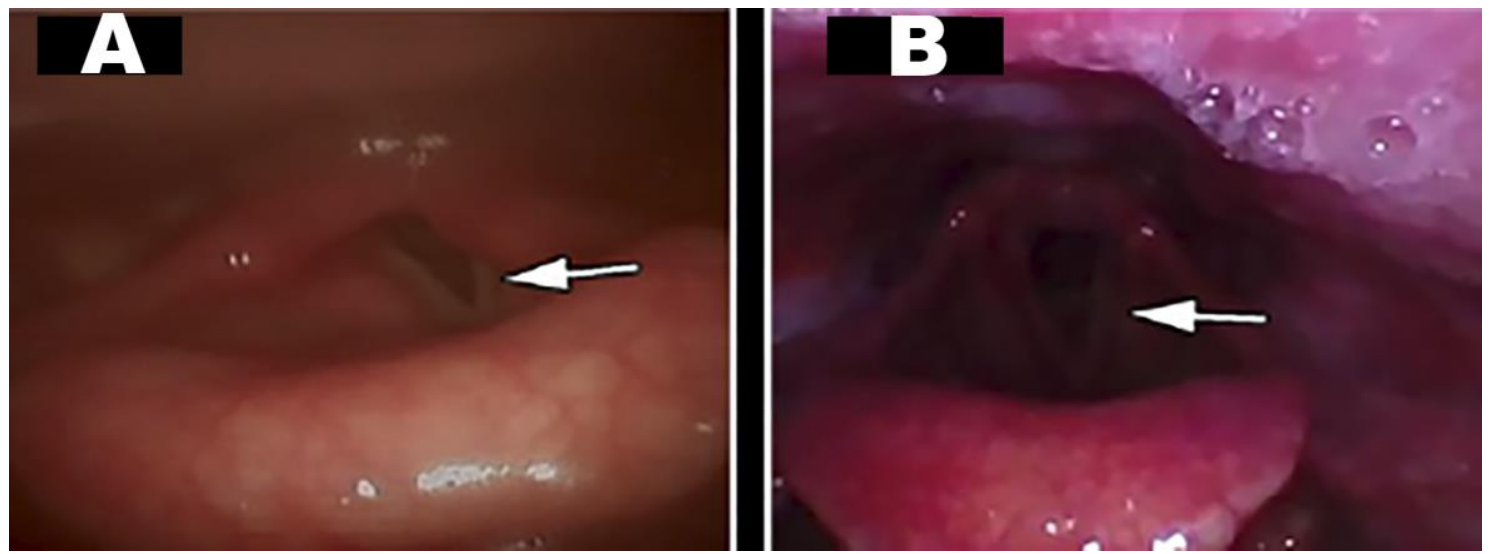

Figure 4. Changes in vocal cord mobility after medical treatment and rehabilitation: (A): (Pre-) left vocal cord in paramedian position during inspiration (white arrow); (B): (Post-) left vocal cord with complete and symmetrical opening (white arrow).

\subsubsection{Neurostimulation}

In the initial evaluation, important cognitive deficits were evidenced: dysexecutive syndrome; severe problems in hierarchical attention; and serious difficulties in immediate, recent, and late verbal and visual memory; as well as deficits in prospective memory. Likewise, there were difficulties in expressive language (especially when naming) and his speech was not very elaborated. There was anosognosia. Emotionally, there was great apathy, with disinterest in things and lack of initiative.

Neurostimulation includes mnesic techniques, electroacoustic stimulation, selfconfidence stimulation, cognition tests and cognitive stimulation, etc.

After working on these neuropsychological deficits for 7 months, the patient became more aware of the injury he had suffered and some of the sequelae that he was still experiencing. A greater acceptance of the new situation was also observed. Sustained attention had increased and his ability to attend to various stimuli at the same time had improved significantly. There was also better control of inhibition against distracting stimuli. The patient was able to follow cross-talk and tolerate noisy surroundings. Little by little, his mood improved, just as his initial apathy diminished. At the memory level he made important advances. Regarding abstract thinking and expressive language, there was 
still a difficulty in communicating highly elaborate thoughts, using wild-card expressions. His capacity for frustration and social interaction also improved. The patient was better able to identify the emotions of others and his own. The cognitive tests carried out confirmed this evolution (Figure 5).
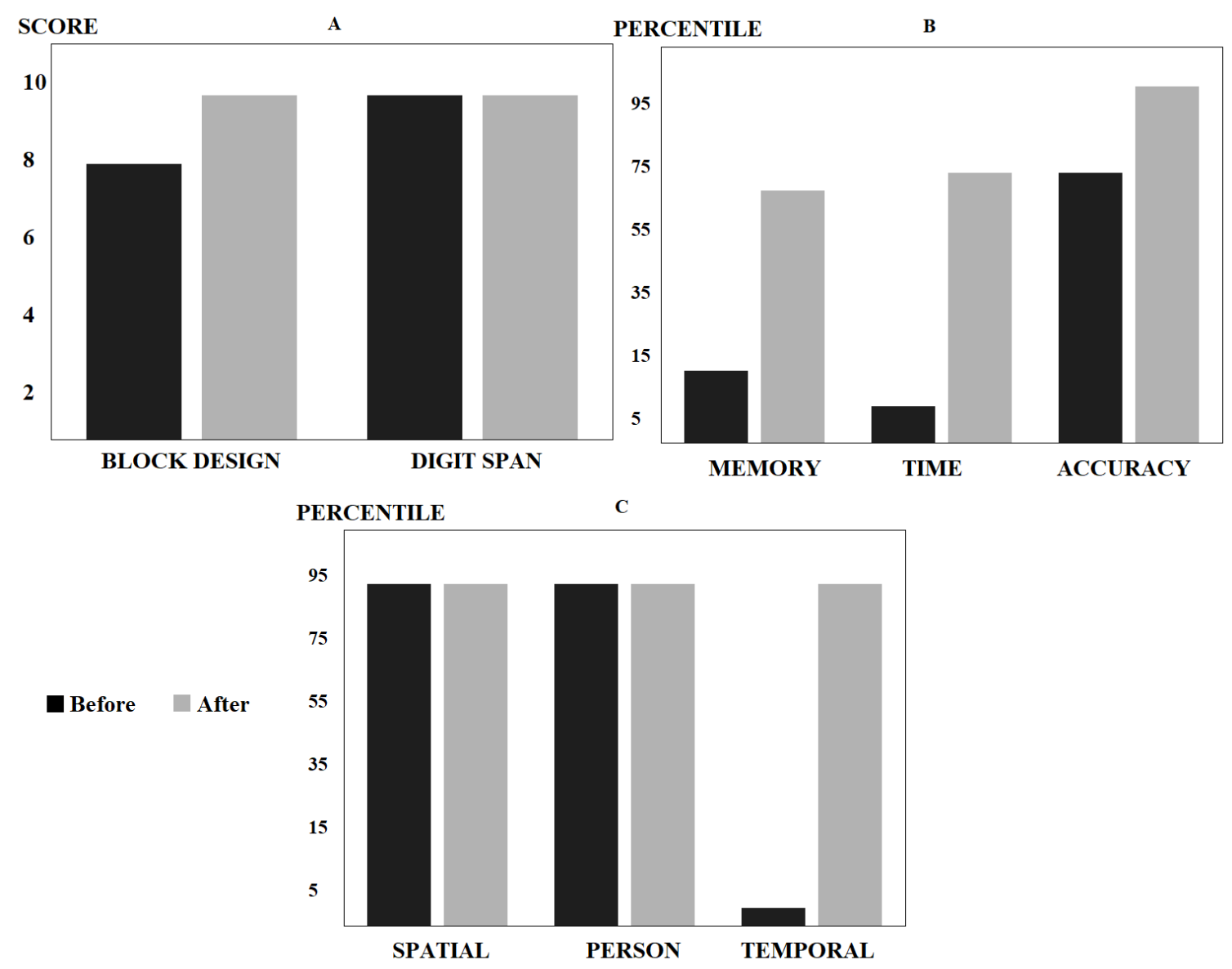

Figure 5. Results in neuropsychological tests before and after treatment: (A) WAIS-III executive functions test, with improvement compatible with an intermediate score; (B) Rey-Osterrieth complex figure test, with a significant percentage advance in memory, time, and precision; and (C) orientation subtest of the revised Barcelona test: good percentiles before and after treatment in spatial and personal orientation and a significant improvement in temporal orientation.

\section{Discussion}

Spontaneous laryngeal reinnervation is possible in lesions that affect the laryngeal nerve, even chronically, at least in animal models $[17,18]$. This can occur at the expense of a healthy residual nerve or adjacent nerves [19]. However, this regeneration is often incomplete and time dependent [20]. As a peripheral nerve, a cellular response of immune cells and Schwann cells (SC) is triggered in the distal nerve after laryngeal nerve injury, known as Wallerian degeneration. During this process, SCs lose their myelin sheaths and undergo dedifferentiation [21]. This allows SCs to subsequently proliferate in response to signals from regenerating axons to ensure that sufficient numbers of SCs are generated to replace those lost during injury and allow them to mediate remyelination [22]. This remyelination has also been observed in the central nervous system [20]. In experimental models, it has been observed that neurons are identified in the nucleus ambiguus ipsilateral to the injury after RLN injury, without affecting other territories of the brainstem or spinal cord. The majority morphology of these neurons is multipolar, with neurons displaced from the nucleus ambiguus [23].

Following recurrent laryngeal nerve injury, a release of several neurotrophic factors occurs, such as brain-derived neurotrophic factor (BDNF), ciliary neurotrophic factor (CNTF), 
neurotrophin-4, line-derived neurotrophic factor glial cell (GDNF), or nerve growth factor (NGF) [24]. That is why it has been theorized that a treatment with neurotrophic factors can stimulate nerve regeneration. During regeneration after RLN injury, differences in neurotrophic factor expression levels may have resulted in preferential reinnervation of the thyroarytenoid versus the posterior cricoarytenoid muscles [25].

According to the knowledge in this area, in patients with unilateral and even bilateral recurrent laryngeal nerve injury, surgical reinnervation strategies have been sought that improve muscle tone and allow medialization of the vocal cords, although with limited results in terms of recovery of their motility $[26,27]$. Research in this field led to medical treatments that can potentially restore laryngeal motility after acquired damage. For example, improvements in laryngeal motility have been reported after early treatment or cotreatment with drugs such as nimodipine or corticosteroids [28-30]. Furthermore, several experimental studies have shown encouraging results using gene transduction vectors or gene therapy using these neurotrophic factors targeting laryngeal muscle structures, motor endplate, and motor neurons [16]. Thus, in rats, the creation of recombinant fusion proteins, consisting of BDNF and GDNF fused with laminin-binding domains (LBD) to prevent diffusion of neurotrophins, and injecting LBD-BDNF, LBD-GDNF, and laminin into a collagen tube that was placed at the ends of the sectioned RLN led to acceptable functional recovery [31].

Our group was the first to demonstrate $[13,14]$ a recovery of the ability to swallow and motility of paralyzed vocal cords (along with recovery from other neurological sequelae) in two adult patients after treatment with GH and speech therapy. Since one of these patients had undergone intensive speech therapy rehabilitation for a period of 15 years without any improvement, we concluded that GH treatment was responsible for the response to rehabilitation. The results presented here support our previous conclusions $[13,14]$. In this sense, we also demonstrated [32] that GH treatment is capable of inducing functional regeneration of the sciatic nerve after its section in rats, with a large proliferation of Schwan cells and complete recovery of nerve histologic morphology, something proven in studies later from other groups [33,34].

It has been shown that GH can act, in an autocrine and/or paracrine manner, as a signaling molecule to promote axonal growth during the development of the nervous system [35]. Even assuming that reinnervation occurred, as clinical data demonstrated, it is unclear how misdirection of the nerve fibers was corrected by GH treatment. However, in addition to the functional recovery of sciatic nerve after its section, we were able to fully promote distal innervation (sensitive, motor, and sphincters) in a child with caudal regression syndrome and sacral agenesis [36]. Therefore, GH administration (by itself or by inducing the expression of other neurotrophic factors) provided the resources to obtaining a response to speech therapy. The existence of spontaneous reinnervation can be completely ruled out in our study because of several reasons. First, while spontaneous recovery may occur after recurrent laryngeal nerve injury, it is unlikely to occur when more proximal vagus nerve involvement exists [25]. In addition, spontaneous innervations have been described in peripheral nerve injuries, but not after CNS lesions, as in the patient in this study and in the other two cases that we previously published $[13,14]$. Finally, but more importantly, the long period of time from the injury until the onset of the treatment clearly excludes spontaneous reinnervation as a factor responsible for the improvements observed.

\section{Conclusions}

Growth hormone actively participates in the recovery from laryngeal paralysis, promoting reinnervation and the gain of muscle tone as well as cognitive sequelae following a traumatic brain injury. It remains to be seen to what extent this hormone could be used in other circumstances where vagus nerve is involved differently than a brain event, such as for local damage or for its use in surgical reinnervation treatments. Although, given its 
effects on axon growth and myelination, it is likely that the administration of this hormone could be promising.

Supplementary Materials: The following are available online at https://www.mdpi.com/article/ 10.3390/reports4030019/s1. Video S1: title: GH and laryngeal paralysis. See the video sent as supplementary material (GH and laryngeal paralysis.mp4).

Author Contributions: Conceptualization: J.G. and J.D. Methodology: J.G., J.D., H.L., C.A. and P.M. Validation: J.G., J.D., H.L., C.A. and P.M. Formal analysis: J.G. and J.D. Data curation: J.G., J.D., H.L., C.A. and P.M. Investigation: J.G. and J.D. Project administration: J.G. and J.D. Supervision: J.G. and J.D. Writing — review and editing: J.G. and J.D. All authors have read and agreed to the published version of the manuscript.

Funding: This work received no external funding.

Institutional Review Board Statement: The study was conducted according to the guidelines of the Declaration of Helsinki, and approved by the Ethics Committee of THE MEDICAL CENTER FOLTRA (2020-017, 7 June 2020).

Informed Consent Statement: Informed consent was obtained from the patient involved in this study.

Data Availability Statement: Archives in the Medical Center Foltra.

Acknowledgments: We acknowledge Foundation Foltra for the help given for the realization of this study.

Conflicts of Interest: The authors declare no conflict of interest.

\section{References}

1. Vachha, B.; Cunnane, M.B.; Mallur, P.; Moonis, G. Losing Your Voice: Etiologies and Imaging Features of Vocal Fold Paralysis. J. Clin. Imaging Sci. 2013, 3, 15. [CrossRef] [PubMed]

2. Venketasubramanian, N.; Seshadri, R.; Chee, N. Vocal Cord Paresis in Acute Ischemic Stroke. Cerebrovasc. Dis. 1999, 9, 157-162. [CrossRef] [PubMed]

3. Fang, T.-J.; Tam, Y.-Y.; Courey, M.S.; Li, H.-Y.; Chiang, H.-C. Unilateral high vagal paralysis: Relationship of the severity of swallowing disturbance and types of injuries. Laryngoscope 2011, 121, 245-249. [CrossRef] [PubMed]

4. Finsterer, J.; Grisold, W. Disorders of the lower cranial nerves. J. Neurosci. Rural. Pr. 2015, 6, 377-391. [CrossRef] [PubMed]

5. Otani, S.; Fujii, H.; Kurasako, N.; Ishizu, T.; Tanaka, T.; Kousogabe, Y.; Tokioka, H.; Namba, M. Recurrent nerve palsy after endotracheal intubation. Masui 1998, 47, 350-355.

6. Hurtado Nazal, C.; Araneda Vilches, A.; Vergara Marín, C.; García Contreras, K.; Napolitano Valenzuela, C.; Badía Ventí, P. Vocal cord paralysis after endotracheal intubation: An uncommon complication of general anesthesia. Braz. J. Anesthesiol. 2018, 68, 637-640. [CrossRef]

7. Chen, C.-T.; Liu, Z.-H.; Lee, S.-T.; Tu, P.-H. Delayed unilateral vocal cord paralysis caused by minor head trauma. Formos. J. Surg. 2016, 49, 230-232. [CrossRef]

8. Garcia, M.D.M.; Magalhães, F.P.; Dadalto, G.B.; De Moura, M.V.T. Avaliação por imagem da paralisia de pregas vocais. Radiol. Bras. 2009, 42, 321-326. [CrossRef]

9. Urculo, E.; Arrazola, M.; Riu, I.; Moyua, A. Delayed glossopharyngeal and vagus nerve paralysis following occipital condyle fracture. J. Neurosurg. 1996, 84, 522-525. [CrossRef]

10. Miyazaki, C.; Katsume, M.; Yamazaki, T.; Aoki, K.; Kuroki, T.; Takasu, N. Unusual occipital condyle fracture with multiple nerve palsies and Wallenberg syndrome. Clin. Neurol. Neurosurg. 2000, 102, 255-258. [CrossRef]

11. Tomar, G.; Kumar, N.; Saxena, A.; Goyal, K. Head injury patient with bilateral vocal cord paralysis: A mistake and a lesson learnt. BMJ Case Rep. 2015, 2015, 9. [CrossRef] [PubMed]

12. Cormier, P.J.; Long, E.R.; Russell, E.J. MR imaging of posterior fossa infarctions: Vascular territories and clinical correlates. Radiogr. 1992, 12, 1079-1096. [CrossRef]

13. Devesa, J.; Reimunde, P.; Devesa, P.; Barberá, M.; Arce, V.M. Growth hormone (GH) and brain trauma. Horm. Behav. 2013, 63, 331-344. [CrossRef]

14. Devesa, J.; Reimunde, P.; Devesa, A.; Souto, S.; Lopez-Amado, M.; Devesa, P.; Arce, V.M. Recovery from neurological sequelae secondary to oncological brain surgery in an adult growth hormone-deficient patient after growth hormone treatment. J. Rehabil. Med. 2009, 41, 775-777. [CrossRef] [PubMed]

15. Bianchi, V.E.; Locatelli, V.; Rizzi, L. Neurotrophic and Neuroregenerative Effects of GH/IGF1. Int. J. Mol. Sci. 2017, 18, 2441. [CrossRef]

16. Araki, K.; Suzuki, H.; Uno, K.; Tomifuji, M.; Shiotani, A. Gene Therapy for Recurrent Laryngeal Nerve Injury. Genes 2018, 9, 316. [CrossRef] [PubMed] 
17. Kupfer, R.A.; Old, M.O.; Oh, S.S.; Feldman, E.L.; Hogikyan, N.D. Spontaneous laryngeal reinnervation following chronic recurrent laryngeal nerve injury. Laryngoscope 2013, 123, 2216-2227. [CrossRef] [PubMed]

18. Halum, S.L.; Bijangi-Vishehsaraei, K.; Saadatzadeh, M.R.; McRae, B.R. Differences in laryngeal neurotrophic factor gene expression after recurrent laryngeal nerve and vagus nerve injuries. Ann. Otol. Rhinol. Laryngol. 2013, 122, 653-663. [CrossRef]

19. Dalgic, A.; Kandogan, T.; Koç, M.; Kulan, C.A.; Yagci, A.; Engin, O.; Aksoy, G.; Ozuer, M.Z. Short-term laryngeal electromyography and histopathological findings after primary reconstruction of the inferior laryngeal nerve in rabbits: Prospective study. J. Laryngol. Otol. 2012, 127, 48-53. [CrossRef]

20. Chen, C.Z.; Neumann, B.; Förster, S.; Franklin, R.J.M. Schwann cell remyelination of the central nervous system: Why does it happen and what are the benefits? Open Biol. 2021, 11, 200352. [CrossRef]

21. Waller, A. Experiments on the Section of the Glosso-Pharyngeal and Hypoglossal Nerves of the Frog, and Observations of the Alterations Produced Thereby in the Structure of Their Primitive Fibres. Edinb. Med Surg. J. 1851, 76, 369-376.

22. Nocera, G.; Jacob, C. Mechanisms of Schwann cell plasticity involved in peripheral nerve repair after injury. Cell. Mol. Life Sci. 2020, 77, 3977-3989. [CrossRef]

23. Hernandez-Morato, I.; Valderrama-Canales, F.J.; Berdugo, G.; Arias, G.; McHanwell, S.; Sañudo, J.; Vázquez, T.; Pascual-Font, A. Reorganization of laryngeal motoneurons after crush injury in the recurrent laryngeal nerve of the rat. J. Anat. 2013, 222, 451-461. [CrossRef]

24. Wang, B.; Yuan, J.; Xu, J.; Xie, J.; Wang, G.; Dong, P. Neurotrophin expression and laryngeal muscle pathophysiology following recurrent laryngeal nerve transection. Mol. Med. Rep. 2016, 13, 1234-1242. [CrossRef] [PubMed]

25. Woodson, G. Spontaneous Laryngeal Reinnervation after Recurrent Laryngeal or Vagus Nerve Injury. Ann. Otol. Rhinol. Laryngol. 2007, 116, 57-65. [CrossRef]

26. Daniero, J.; Garrett, C.G.; Francis, D.O. Framework Surgery for Treatment of Unilateral Vocal Fold Paralysis. Curr. Otorhinolaryngol. Rep. 2014, 2, 119-130. [CrossRef] [PubMed]

27. Anthony, B.; Parker, N.; Patel, R.; Halum, S. Surgical Considerations for Laryngeal Reinnervation and Future Research Directions. Curr. Otorhinolaryngol. Rep. 2020, 8, 224-229. [CrossRef]

28. Mattsson, P.; Frostell, Å.; Björck, G.; Persson, J.K.E.; Hakim, R.; Zedenius, J.; Svensson, M. Recovery of Voice After Reconstruction of the Recurrent Laryngeal Nerve and Adjuvant Nimodipine. World J. Surg. 2017, 42, 632-638. [CrossRef] [PubMed]

29. Lin, R.J.; Klein-Fedyshin, M.; Rosen, C.A. Nimodipine improves vocal fold and facial motion recovery after injury: A systematic review and meta-analysis. Laryngoscope 2019, 129, 943-951. [CrossRef]

30. Ichimura, H.; Ishikawa, S.; Yamamoto, T.; Onizuka, M.; Inadome, Y.; Noguchi, M.; Sakakibara, Y. Effectiveness of Steroid Treatment for Hoarseness Caused by Idiopathic Fibrosing Mediastinitis: Report of a Case. Surg. Today 2006, 36, 382-384. [CrossRef] [PubMed]

31. Wang, B.; Yuan, J.; Chen, X.; Xu, J.; Li, Y.; Dong, P. Functional regeneration of the transected recurrent laryngeal nerve using a collagen scaffold loaded with laminin and laminin-binding BDNF and GDNF. Sci. Rep. 2016, 6, 32292. [CrossRef] [PubMed]

32. Devesa, P.; Gelabert, M.; Gallego, R.; Relova, J.L.; Devesa, J.; Arce, V.M.; Gonźlez-Mosquera, T. Growth hormone treatment enhances the functional recovery of sciatic nerves after transection and repair. Muscle Nerve 2012, 45, 385-392. [CrossRef] [PubMed]

33. Tuffaha, S.H.; Budihardjo, J.D.; Sarhane, K.A.; Khusheim, M.; Song, D.; Broyles, J.M.; Salvatori, R.; Means, K.; Higgins, J.P.; Shores, J.T.; et al. Growth Hormone Therapy Accelerates Axonal Regeneration, Promotes Motor Reinnervation, and Reduces Muscle Atrophy following Peripheral Nerve Injury. Plast. Reconstr. Surg. 2016, 137, 1771-1780. [CrossRef] [PubMed]

34. Lopez, J.; Quan, A.; Budihardjo, J.; Xiang, S.; Wang, H.; Koshy, K.; Cashman, C.; Lee, W.P.A.; Hoke, A.; Tuffaha, S.; et al. Growth Hormone Improves Nerve Regeneration, Muscle Re-innervation, and Functional Outcomes After Chronic Denervation Injury. Sci. Rep. 2019, 9, 1-11. [CrossRef] [PubMed]

35. Baudet, M.-L.; Rattray, D.; Martin, B.T.; Harvey, S. Growth Hormone Promotes Axon Growth in the Developing Nervous System. Endocrinology 2009, 150, 2758-2766. [CrossRef]

36. Devesa, J.; Alonso, A.; López, N.; García, J.; Puell, C.I.; Pablos, T.; Devesa, P. Growth Hormone (GH) and Rehabilitation Promoted Distal Innervation in a Child Affected by Caudal Regression Syndrome. Int. J. Mol. Sci. 2017, 18, 230. [CrossRef] 